\title{
UN RELATO KIMBANDISTA, UMBANDISTA Y BATUQUEIRO DESDE ARGENTINA
}

\author{
Maria Azul di Baja ${ }^{1}$
}

DOI 10.26512/revistacalundu.v3i2.27167

Soy Azul, hija de Oxúm, Mae Pequeña de la casa de Santo de la Mae Patricia de Oyá Timboá del Ilé Nueva Conciencia.

Conocí la casa de Patricia a mis 17 años, cuando todavía estudiaba en la secundaria. En ese entonces la relación con mi familia era muy distante, casi no hablaba de las cosas que me pasaban, ni me preocupaba por saber qué les sucedía a ellos. Yo solo quería estar dentro de la escuela o fuera de mi casa, ya que ahí (en mi casa) no me sentía cómoda.

Un día mi mamá nos dice que iban a venir a casa a hacer una limpieza y que si queríamos ayudar. Yo sólo estaba pensando en ir a la casa de mi novio, pero ayudé a preparar las cosas haciendo caso a las indicaciones que nos habían dado.

Cuando estaba por irme, llegó la Mae Patricia: una mujer de cabellos colorados y enrulados, quién se presentó muy amablemente y cuya mirada y expresión llamaron mi atención. Saludé a todas las personas que llegaron con ella y me fui.

Una noche, durante la cena, mi mamá y mi hermana comenzaron a discutir y mi hermana mostró señales visibles de que estaba pasando por un momento de angustia muy grande. Fue así como mi mamá la tomó del brazo y le dijo "vamos a lo de la Mae Patricia".

Durante semanas posteriores ellas no pararon de hablar de la casa de la Mae y de lo que ellas llamaban "entidades". Sus conversaciones se volvieron tan cerradas que yo no podía participar de ellas. Así fue como decidí preguntar y me contestaron que allí incorporaban entidades que ya no estaban en este plano y que éstas se sentaban a fumar, tomar y hablar. Frente a este relato imaginé una escena en la cual las comunidades originarias entraban en trance, incorporaban a sus antepasados sentados en una ronda y fumando pipa. Su relato no me pareció extraño ni descabellado, pero sí despertó mi curiosidad y, a su vez, el hecho de no poder formar parte de las conversaciones sobre el tema me estaba incomodando. Por ello, pedí que me llevaran para conocer.

\footnotetext{
${ }^{1}$ Mãe Pequeña del Ilé Nueva Conciencia.
} 
Recuerdo a la primera sesión a la que fui, que la llamaban "Kimbanda". Ni bien llegué, todas las personas, que no eran muchas, se mostraron con mucha amabilidad. Me explicaron brevemente lo que sucedería, me pidieron que me sentara fuera de la ronda en un lugar determinado y que, ante cualquier duda o acontecimiento, preguntara.

Se apagaron las luces y comenzó la sesión. Las personas comenzaron a cantar una canción en portugués y la Mae Patricia comenzó a girar en el medio hasta que algo sucedió en su cuerpo. Fue como si hubiese recibido un golpe fuerte en la nuca que la obligó a arrodillarse por el impulso. La Mae Patricia se levantó y comenzó a caminar de una manera extraña con las rodillas semiflexionadas y las manos juntas por detrás de la espalda. Ese ser que se encontraba en el medio de la ronda y se desplazaba por fuera de ella ya no era la Mae de hace minutos atrás.

Cuando regresó al espacio (ese ser o entidad), saludó a todas las personas y se sentó en un sillón que prepararon para él. En ronda, todos sentados en el suelo, el señor hablando en portugués comenzó a preguntar cómo se sentían y les dio consejos frente a los problemas que cada uno contaba. Durante la ronda, él me miró a los ojos y me pidió que me acercara, me enseñó cómo saludarlo y me preguntó si había algo que quería saber. Le pregunté por mi papá, quién había fallecido cuando tenía 6 años. Pregunté si lo volvería a ver. Él, con una mirada intensa y honesta, me respondió que no. Me quedé en silencio unos segundos y lo abracé muy fuerte y comencé a llorar. Él se quedó abrazándome hasta que me calmé, nos miramos nuevamente a los ojos y sentí que con ellos me estaba sonriendo con ternura, volví a abrazarlo y besé su mejilla. Algo que pareció extrañar al resto, ya que nadie solía hacerlo por respeto. Pero yo, desde mi desconocimiento e ingenuidad me lo había permitido. Tiempo después entendí quién era él, cuál era su rol y cuán osada había sido al haberlo hecho. Él fue y sigue siendo como un padre para mí.

Luego se fue ese señor y llegó la entidad mujer de la Mae Patricia. La señora María Padilha entró bailando al salón con una sensualidad que jamás había visto. La misma captó mi interés ya que en ese momento la danza era algo que me apasionaba. Cuando se sentó comenzó a hablar de la mujer y la fuerza que ésta tiene. Luego me daría cuenta de que ella sería quién levantaría el primer bastión del feminismo en mi vida: esa entidad había liberado, en vidas anteriores, a mujeres que habían sido esclavas sexuales incitándolas a que se revelaran contra los hombres que las explotaban. Ella me enseñó que las mujeres no somos débiles, sino que somos sumamente poderosas y que 
tenemos la capacidad, a diferencia de los hombres, de dar vida si así lo queremos. Como entidad y reina que es en el plano astral, jamás aceptó que nos arrodilláramos ante ella, como si fuésemos esclavos. Por el contrario, ella quiere que seamos hombres y mujeres fuertes, que no nos arrodillemos ante nadie. Con ella aprendí a erguirme en el mundo como mujer adulta.

Luego de esa experiencia me fasciné con las entidades de la casa y la forma en que éstas se relacionaban con las personas, tanto de Kimbanda como de Umbanda, como símbolo de fuerza y resistencia. Cada una tenía una historia para contar que llevaba consigo una enseñanza a partir de la propia experiencia. Cada vez que las personas tanto de la casa como externas traían una problemática, ellos tenían una palabra justa para ayudarlos a sentirse mejor o, inclusive, resolver su situación. Así, entendí la potencia que tiene la palabra para transformar la realidad.

Con el pasar del tiempo, conocí a mis guías y ancestros que me cuidan y acompañan en mi camino. También fui asistiendo a las entidades para que pudieran trabajar con las personas, hasta que el Señor de la Mae Patricia y la señora María Padilha me nombraron su cambona, dándome el honor de asistirlos. Fue así como me fueron enseñando a trabajar a partir de la palabra con las personas, sobre la escucha, el entendimiento de las situaciones y cómo decir las cosas de manera en que se pueda interpelar al otro.

Nosotros cultuábamos a los Orixás en la Línea de Batuque y realizábamos los rituales correspondientes al culto, vinculándonos con su energía en el cuarto santo y sus reinos, pidiéndoles su intervención en problemas de salud o agradeciéndoles por su ayuda y presencia en nuestras vidas. Mi Mae Oxúm, desde el comienzo fue inflexible conmigo y no permitió que delegase ninguna responsabilidad enseñándome a transitar la vida con seguridad y firmeza, acompañándome durante todo mi crecimiento a partir del compromiso, la perseverancia, la sinceridad y el amor.

Tanto los Orixás como las entidades de la casa nos transmitían una filosofía de vida, enseñándonos a ser mejores personas y superar nuestros problemas desde el reconocimiento, la autorreflexión y la acción en pos de atravesar las adversidades. Nos enseñaban a ser guerreros.

En un momento de mi vida me encontraba estudiando la carrera de medicina en respuesta a un mandato familiar vinculado a la ausencia de mi papá ( él había sido médico), y me sentía confundida al respecto. Fue así como el Señor de la Mae Patricia 
(a quien cariñosamente le decimos "Viejo", por su antigüedad, sabiduría y lugar paternal que ocupa en nuestra vida) me miró nuevamente a los ojos y me aconsejó que dejara la carrera de medicina y que estudiara algo que tuviese que ver con la actuación y la danza; es decir, algo relacionado con aquello que me apasionaba. Fue así como me inscribí en la carrera de actuación y no pude ingresar. Luego de mi segundo intento y casi azarosamente descubrí la Expresión Corporal, y me enamoré de ella dejando de lado el teatro.

Con el transcurso del tiempo mi vínculo con el arte se fue transformando para dejar de interesarme su rol escénico y enfocarme en su capacidad de transformación. Recordando así la valoración que el Señor le da al arte en función de la capacidad que ésta tiene para decir todo aquello que no podíamos poner en palabras y, desde ahí, procesar ciertas cosas y generar una modificación en uno mismo y en los otros.

Hasta el día de hoy encuentro al templo no solo como un espacio de contención, sino de constante formación. Luego de 13 años, a partir de mi vínculo con lo espiritual, encontré una manera enriquecedora de transitar mi vida: los ancestros me eligieron y me dieron el honor de ser sacerdotisa y poder vincularme con ellos desde un lugar más íntimo y ayudar así a las personas, terminé una carrera universitaria recibiéndome de profesora de Expresión Corporal y descubrí una pasión en trabajar en territorio con las problemáticas sociales a partir de la escucha, la palabra, la intervención y el arte, tal como me enseñaron la Mae Patricia, mis hermanos y ancestros.

Hoy en día, en el templo, si bien seguimos invocando a las entidades para aprender de ellas, ya no cultuamos a los Orixás como tales, cambiando así nuestra forma de culto e incorporando nuevas experiencias y enseñanzas. Pero esa ya es otra historia que ameritaría un nuevo relato.

Recebido em:15/09/2019

Aceito em: 20/09/2019 